This is a postprint version of the following published document:

Martin, O., Pastoriza, A., Mikes, F., \& Baselga, J. (2002). Water absorption in epoxy resins by electronic energy transfert. Polymer International, Special Issue: Polymers in the Third Millennium, 51 (11), pp. 1207-1210.

DOI: $10.1002 /$ pi.891

(C) Society of Chemical Industry, 2002 


\title{
Water absorption in epoxy resins by electronic energy transfer ${ }^{\dagger}$
}

\author{
O Martin, ${ }^{1}$ A Pastoriza, ${ }^{2} \mathrm{~F}_{1}$ Mikes ${ }^{3}$ and J Baselga ${ }^{1 *}$ \\ Instituto Tecnológico de Química y Materiales, Universidad Carlos III de Madrid, Leganés, 28911, Spain \\ Facultad de Ciencias, UNED, 28040 Madrid, Spain \\ ${ }^{3}$ Polytechnic University, Six MetroTech Center, Brooklyn, NY 11201, USA
}

\begin{abstract}
:
Water absorption of an epoxy resin was studied by steady-state fluorescence spectroscopy and gravimetry. It was found that the intrinsic emission of the epoxy resin could be modified selecting an adequate excitation wavelength. The epoxy component of the resin was labelled with a trans-4nitro-4'-aminostilbene fluorescent probe. Using an excitation wavelength of $340 \mathrm{~nm}$ it was possible to induce energy transfer to the suitable acceptor trans-4-nitro-4'-dialkylaminostilbene (NDAS). The relative fluorescence intensity $/{ }_{433} / 1_{596}$ was used as a convenient means to follow the quenching effect of water on the emission ofNDAS when excited via energy transfer. It was found that both the relative intensity and the water content increase linearly with the square root of diffusion time in the early stages of the process. The apparent Stem-Volmer constants for the quenching of the fluorophore, when excited directly in a fluid THF solution or in the polymer matrix, were very similar but lower than when the fluorophore was excited via energy transfer. It was concluded that, at least in the early stages of the water diffusion process, the interchromophoric distance should increase.
\end{abstract}

Keywords: epoxy resins; non-radiative energy transfer; water absorption

\section{INTRODUCTION}

Water absorption is an important phenomenon in polymers and composite materials and has a number of effects on their properties. For example, the presence of water degrades the matrix/reinforcement interface in composites due to the high surface energy of the fibre surfaces. ${ }^{1,2}$ In bulk polymer materials and coatings the main effect of water is the plastification of the polymer with the associated lowering of thermal and mechanical properties. ${ }^{3-5}$ The water uptake of epoxy resins has been traditionally studied by gravimetric methods. More recently, FTIR, ${ }^{5}$ FT-NIR ${ }^{6}$ and fluorescence ${ }^{7,8}$ have been applied to monitor this phenomenon. In this paper we propose to make use of the intrinsic photophysical properties of bisphenol A diglycidyl ether epoxy polymers (DGEBA) and, specifically, their donor behaviour against a suitable fluorescent label such as trans-4-nitro-4'-aminostilbene (NAS).

\section{EXPERIMENTAL}

Trans-4-nitro-4'-aminostilbene (NAS) was prepared by reduction of trans- $4,4^{\prime}$-dinitrostilbene according to of the epoxy component (bisphenol A diglycidyl ether, DGEBA, Aldrich) with 4-nitro-4'-aminostilbene consisted of the addition reaction between the aromatic amine of the label and the epoxide group: in the labelling reaction NAS is transformed into 4-nitro-4'dialkylaminostilbene (NDAS). The structure of the labelled epoxy-(NDAS) is presented in Scheme I. The labelling reaction was carried out mixing appropriate amounts of both components and stirring for $16 \mathrm{~h}$ at $160^{\circ} \mathrm{C}$; the efficiency of the labelling was followed by TLC and SEC. The labelling experimental conditions were set after studying a model reaction between NAS and a monofunctional epoxy molecule (PEG, phenyl glycidyl ether) of similar reactivity present in great excess (10:1 mole fraction). According to TLC, two

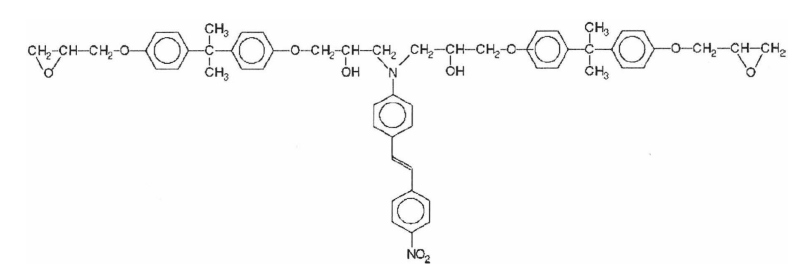

Scheme 1. Chemical structure of DGEBA - labelled with trans-4-nitro-4'- 
spots were obtained at the beginning of the reaction, corresponding to free NAS and free PEG $\left(\mathrm{R}_{\mathrm{f}}(\mathrm{PEG})=0.44 \mathrm{R}_{\mathrm{f}}(\mathrm{NAS})=0.26\right.$ in hexane/ethyl acet ate/ethanol 1:1:0.3). As reaction proceeded, two more spots $\quad\left(\mathrm{R}_{\mathrm{f}}(\mathrm{NAS}+1 \mathrm{PEG})=0.20, \mathrm{R}_{\mathrm{f}}(\mathrm{NAS}+2 \mathrm{PEG})=\right.$ 0.05) appeared, corresponding to the addition of one and two molecules of PEG. At long reaction times, but less than $16 \mathrm{~h}$, the spots corresponding to free NAS and NAS + 1PEG disappeared leaving the spot with $R_{f}=0.05$. It was concluded that, under such conditions, the reaction mixture did not contain any unreacted fluorescent label and that all the labels contained two epoxide groups. The concentration of label in the DGEBA was $1.2 \times 10^{-3} \mathrm{~mol} \mathrm{~kg}^{-1}$ of epoxy.

The selected epoxy system was a commercial formulation supplied by Gairesa SA (Spain), Bepox 626. The first component of this formulation was a mixture of DGEBA $(10 \% \mathrm{w} / \mathrm{w})$ and the product of reaction between bisphenol A epoxy resin and a longchain epoxydized polyol. An aduct of meta-xylene diamine was used as hardener. A small amount of labelled first component was dissolved in the unlabelled component to achieve the desired final label concentration of $1.72 \times 10^{-4} \mathrm{~mol} \mathrm{~kg}^{-1}$ of resin. The solution was mixed stoichiometrically with the second component, degassed at vacuum for $5 \mathrm{~min}$, cured at room temperature for $24 \mathrm{~h}$ in an open mould, and subsequently postcured at $60^{\circ} \mathrm{C}$ for $1 \mathrm{~h}$. The glass transition temperature of the fully cured system was $54^{\circ} \mathrm{C}$ as determined by DSC (Perkin Elmer, $10 \mathrm{~K}$ $\left.\min ^{-1}\right)$.

Water uptake was determined gravimetrically at $22^{\circ} \mathrm{C}$ on rectangular specimens of dimensions $375 \times 10 \times 1.1 \mathrm{~mm}^{3}$. Prior immersion in high purity water (Barnstead, UK), specimens were cleaned with trichloroethylene to remove traces of the releasing agent used in the mould. The weight of specimens was determined as a function of immersion time and the amount of water determined as $\% w=100 \times\left(m_{0}-\right.$ $m) / m_{0}$, where $m_{0}$ and $m$ are the initial and actual weights of the specimens, respectively. Special care was taken to store samples in dark before and during

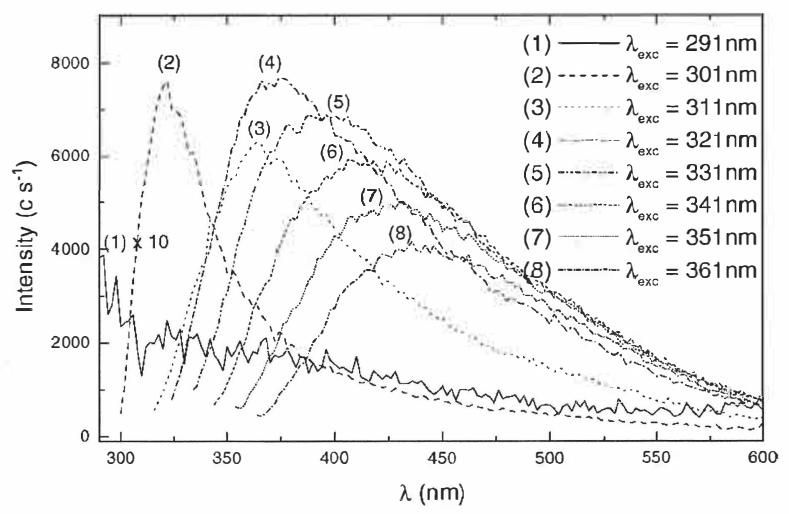

Figure 1. Emission fluorescence spectra of bulk DGEBA at various excitation wavelengths ranging from $\lambda_{\text {exc }}=291 \mathrm{~nm}(1)$ to $361 \mathrm{~nm}$ (8). the water uptake experiments to avoid induction of the cis-trans photoisomerization process.

Fluorescence measurements were performed on an Edinburgh Instruments (UK) fluorimeter equipped with monochromators in both the excitation and emission channels. Excitation light of 340 or $420 \mathrm{~nm}$ was provided by a 400-watt xenon lamp. Emission and excitation slits were set at $2 \mathrm{~nm}$. Corrected fluorescence spectra were recorded using the standard fibre-optic accessory in the range $350-670 \mathrm{~nm}$. Control experiments checked that the absorbed light at $340 \mathrm{~nm}$ under the optical conditions of the spectrometer was not enough to photoinduce photoisomerization.

\section{RESULTS AND DISCUSSION}

The unlabelled epoxy first component presents an intrinsic fluorescence dependent on emission or excitation wavelengths, which is associated with the presence of DGEBA units. In Figs 1 and 2, emission and excitation spectra of pure DGEBA are presented as a function of excitation or emission wavelength. In solution, DGEBA presents an absorption band at $291 \mathrm{~nm}$ and a relatively narrow emission band centred at $300 \mathrm{~nm}$. In the bulk state the emission band is shifted towards $320 \mathrm{~nm}$ and the corresponding absorption shifts about $10 \mathrm{~nm}$ to the red, as can be observed in graph (2) of Fig 1, where that emission band is only observed when excited at $301 \mathrm{~nm}$. In the bulk state, epoxy fluorescence presents other interesting features such as, for example, a broadening and continuous shifting to the red of its emission as excitation is increased from $301 \mathrm{~nm}$; at the same time, emission intensity decreases with excitation wavelength. The excitation spectra, presented in Fig 2, show that the intrinsic emission of epoxy component has two contributions: a contribution from species absorbing at $301 \mathrm{~nm}$ and a contribution from species that absorb in a wider wavelength range. As a tentative explanation of the observed behaviour we suggest that absorbance at $301 \mathrm{~nm}$ corresponds to isolated DGEBA units; the

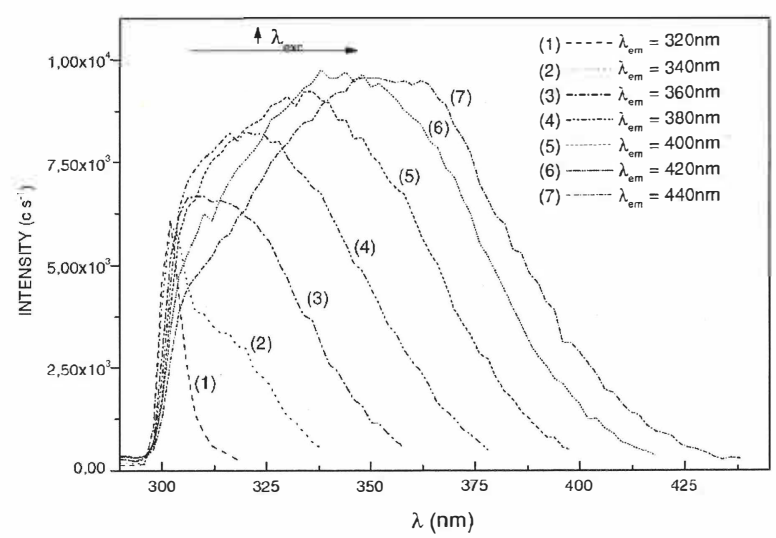

Figure 2. Excitation fluorescene spectra of bulk DGEBA at various emission wavelengths ranging from $\lambda_{\mathrm{em}}=300 \mathrm{~nm}$ (1) to $440 \mathrm{~nm}$ (7). 


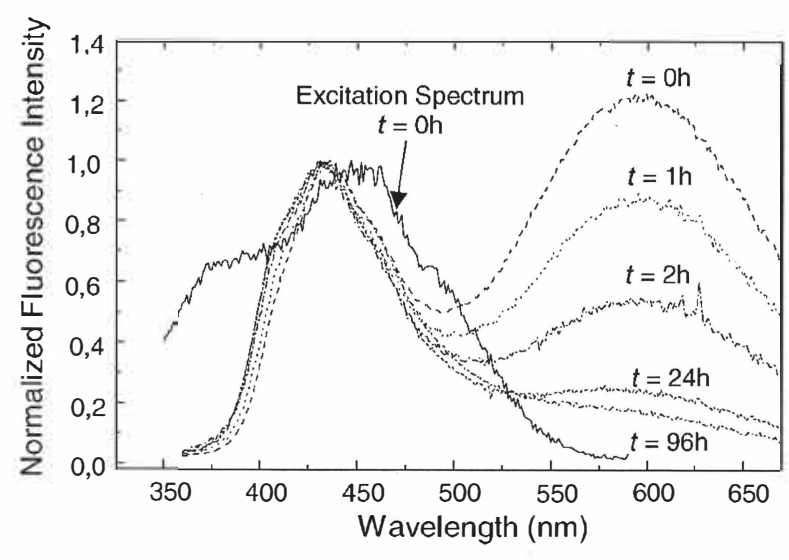

Figure 3. Normalized emission $\left(\lambda_{\text {exc }}=340 \mathrm{~nm}\right.$ ) spectra of NDAS-labelled epoxy ([NDAS] $=1.7210^{-4} \mathrm{~mol} \mathrm{~kg}^{-1}$ ) and excitation spectrum $\left(\lambda_{\mathrm{em}}=600 \mathrm{~nm}\right)$ before immersion $(t=0 \mathrm{~h})$ and emission spectra $\left(\lambda_{\text {exc }}=340 \mathrm{~nm}\right)$ at various water immersion times.

second contribution may be assigned to DGEBA ground-state aggregates. To the authors' knowledge, only in Reference 10 is a similar assignment reported although the contribution of a triplet excimer is also mentioned. The excitation-dependent emission behaviour may be associated with the aggregation number of DGEBA units and some advantage can be taken from it as an intrinsic source for energy-transfer experiments.

Figures 1 and 2 show that if bulk epoxy resin is excited at $340 \mathrm{~nm}$, a broad emission can be observed at around $400 \mathrm{~nm}$, a wavelength range in which the NDAS label strongly absorbs, and almost no emission at $600 \mathrm{~nm}$, where NDAS strongly emits

The emission $\left(\lambda_{\text {exc }}=340 \mathrm{~nm}\right)$ and excitation $\left(\lambda_{\mathrm{em}}=600 \mathrm{~nm}\right)$ spectra of epoxy resins labelled with NDAS before immersion and the emission spectra at different immersion times are presented in Fig 3. The emission spectrum obtained before immersion $(t=0)$ consists of two broad bands centred at approximately $430 \mathrm{~nm}$ and $600 \mathrm{~nm}$. The first band, according to Fig 1 , should be assigned to the intrinsic emission of the epoxy matrix; the second should be assigned to emission of the NDAS moiety. NDAS has a chemical structure very similar to that of trans-4-nitro-4'dimethylaminostilbene (DMANS) whose photophysical properties have been reported ${ }^{1,12}$ and that has been recently used for monitoring polymerization reactions. ${ }^{13,14}$ NDAS essentially differs with respect to DMANS in the length of the alkyl substituent of the aromatic amino group. Its fluorescence properties should be therefore very similar. For example, an absorption maximum for DMANS at $419 \mathrm{~nm}$ and an emission maximum at $616 \mathrm{~nm}$ in THF were reported $^{13}$, which are almost coincident with data for NDAS presented in this work, as can be seen in figure 3. Excitation spectrum (Fig 3 ) at $\lambda_{\text {exc }}=600 \mathrm{~nm}$ consists of two overlapped bands. The blue-shifted band (around $380 \mathrm{~nm}$ ) is assigned to the absorption of epoxy aggregates (Fig 2) and the red-shifted band (around $450 \mathrm{~nm}$ ) corresponds to the residual absorption of the NDAS. Therefore, it can be concluded from Fig 3 that epoxy aggregates may act as donors and NDAS moieties as acceptors of electronic energy in the bulk state.

DMANS and NDAS belong to the group of $\mathrm{D}-\pi-\mathrm{A}$ polyenes for which a TICT state has been established. ${ }^{15}$ Due to the high excited-state dipole moment, in highly polar environments, such as water, excited states are quenched. If absolute fluorescence intensity methods are used, the quenching by water precludes the use of these molecules as water sensors. ${ }^{13}$ However in this case, since the epoxy component provides a continuous source of electronic energy, calculation of the relative variation of acceptor emission intensity may be a convenient method for monitoring water absorption.

In Fig 3, the emission spectra of NDAS-labelled epoxy are presented at several immersion times $(0,1$, 2,24 and 96h) in water. It can be seen that, as absorption of water takes place, the relative emission intensity of NDAS moiety decreases. In Fig 4, the amount of absorbed water as measured gravimetrically and the relative fluorescence intensity $I_{433} / I_{596}$ as a function of the square root of immersion time are presented.

Water absorption is commonly studied as a diffusion-controlled process. Solving Fick's law under the appropriate boundary conditions ${ }^{16}$ (sheet of infinite length), it is possible to find a linear relationship between the amount of absorbed water and the square root of the diffusion time, as obtained for the experimental data in Fig 4.

Alternatively, emission spectra of NDAS were obtained using direct excitation at $420 \mathrm{~nm}$. The fluorescence spectra (not shown) were very similar to the red part of the spectra presented in Fig 3. A decrease of fluorescence intensity in parallel behaviour to that depicted in Fig 3 was also found. Analysis of the quenching effect of water on emission of NDAS, either with direct excitation or via energy transfer, was made in terms of Stern-Volmer plots presented in Fig 5. In

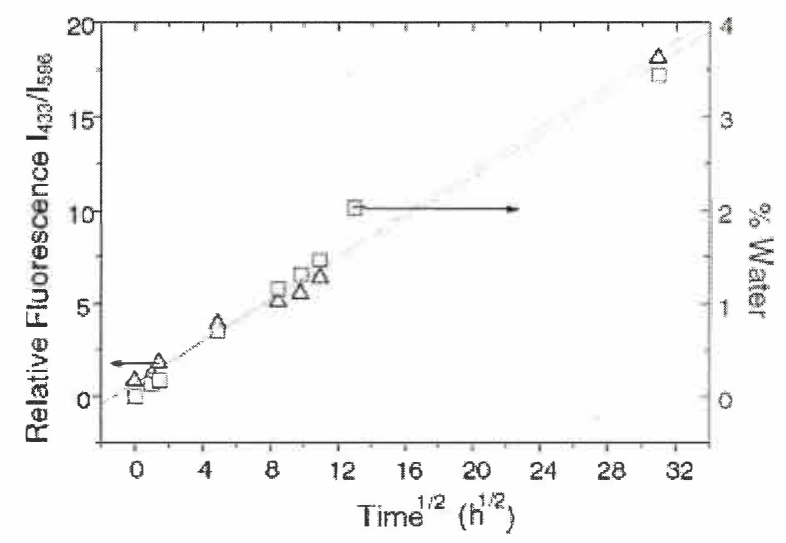

Figure 4. Relative fluorescence intensity $(\Delta)$ and $\%$ water uptake $(\square)$ of BP626 epoxy resin doped with NAS as a function of the square root of the immersion time in distilled water at $23^{\circ} \mathrm{C}$. 


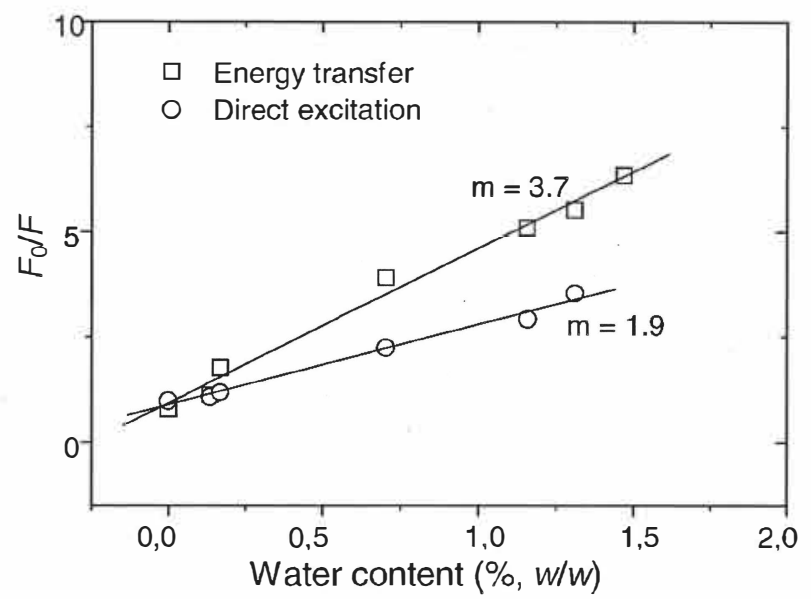

Figure 5. Stern-Volmer plots of the water quenching of NDAS-labelled epoxy resin: $(\square)$ energy-transfer excitation at $340 \mathrm{~nm}$; $(\bigcirc)$ direct excitation at $420 \mathrm{~nm}$.

the water concentration interval studied, there is a linear trend for both ranges of data but the slopes are notably different. The slope corresponding to the data obtained by direct excitation should be related to the quenching constant of water, if appropriate units are used. If excitation is made via energy transfer, a greater slope than this is obtained. In separate experiments, the quenching effect of water on NAS was studied in THF solutions and a slope of 2.0 was obtained. Therefore, the apparent quenching constants in fluid solution (NAS) and in a rigid matrix (NDAS) are very similar, suggesting that the same static quenching mechanism operates.

In the case of excitation via energy transfer, in addition to the quenching of NDAS excited state a second phenomenon could explain the high slope obtained in Fig 5. Efficiency of energy transfer strongly depends on donor-acceptor distance. The rate constant for energy transfer inversely depends on the sixth power of the donor-acceptor distance. ${ }^{17}$ Slight perturbation of the interchromophoric distance due to some swelling of the matrix may decrease the efficiency of energy transfer consequently increasing the ratio $I_{433} / I_{596}$. This phenomenon opens a new perspective to study the dynamics of water diffusion in polymer matrices.

\section{CONCLUSIONS}

The characteristic emission of epoxy resins can be modified by selecting an adequate excitation wavelength and can be used as a donor source for energy- transfer experiments with a trans-4-nitro-4-dialkylaminostilbene fluorescent moiety.

For the donor-acceptor pair studied in this work, the relative emission $I_{433} / I_{596}$ has been proved to be a suitable index for monitoring water uptake phenomena. It was found that both the relative intensity and the water content increase linearly with the square root of diffusion time in the early stages of the process.

The apparent quenching constants have been measured in three cases: using direct excitation of the fluorophore in fluid solution, using direct excitation of the fluorophore in the solid polymer matrix, and exciting the fluorophore via energy transfer. In the first two cases, the apparent quenching constants were very similar but lower than in the third case. This deviation was explained by considering the increase of the interchromophoric distance as water enters the polymer matrix. This finding opens a new perspective to study the dynamics of the water diffusion process.

\section{ACKNOWLEDGEMENTS}

Authors gratefully acknowledge project BE97-4472 (Brite EuRam) and to CAM (Pricit, Programa Grupos Estratégicos) for financial support.

\section{REFERENCES}

1 Dibenedetto AT and Lex PJ, Polym Engng Sci 29:543 (1989).

2 Viña J, García EA, Argüelles A and Viña I, J Mater Sci Lett 19:579 (2000).

3 Sharpe LH, $\mathcal{J}$ Adhes 4:51 (1972).

4 Gledhill RA and Kinloch AJ, $\mathcal{F}$ Adhes 6:315 (1974).

5 DeNèeve B and Shanahan MER, Polymer 34:5099 (1993).

6 Musto P, Mascia L, Ragosta G, Scarinzi G and Villano P, Polymer 41:565 (2000).

7 Sung CSP and Sung NH, Mater Sci Engng A162:241 (1993).

8 Miller KE, Krueger RH and Torkelson JM, f Polym Sci, Polym Phys 33:2343 (1995).

9 Mikes F, Baselga J and Paz-Abuin S, Eur Polym (accepted).

10 Philips D and Roberts AJ, Photophysics of synthetic polymers, The Royal Institution, London, p 128 (1982).

11 Papper V, Pines D, Likhtenshtein G and Pines E, F Photochem Photobiol A, Chem 111:87 (1997).

12 Salvador EF, Sintesis y estudio fotofísico de sondas fluorescentes. Seguimiento de procesos de fotopolimerización y fotodegradación. Aplicación en adhesivos, PhD Thesis, Univ Complutense de Madrid, Madrid (2001).

13 Peinado C, Salvador EF, Baselga J and Catalina F, Macromol Chem Phys 202:1924-1934 (2001).

14 Popielarz R and Neckers DC, Proc Rad Technol 1:271 (1996).

15 Rettig W and Majenz W, Chem Phys Lett 154:335 (1989).

16 Crank J, The mathematics of diffusion, Oxford University Press, Oxford (1993).

17 Lakowicz JR, Principles of fluorescence spectroscopy, 2nd edn, Kluwer Academic, New York, p 368 (1999). 